\title{
Anticoncepción de Emergencia y Fallo del Tribunal Constitucional: ¿Avance o Retroceso?
}

En materia de salud pública, el debate nacional se ha centrado últimamente en el fallo del Tribunal Constitucional respecto de la anticoncepción de emergencia y, puntualmente, respecto de la controvertida "píldora del día después". Para analizar este tema con la mayor objetividad posible, es necesario hacer un repaso de lo que ha sido la historia sanitaria de Chile en este campo.

Ciertamente, hace 40 ó 50 años, los desafíos en salud pública en nuestro país eran muy distintos a los que enfrentamos en el siglo XXI. En lo que respecta a la salud maternoinfantil, los grandes temas eran la morbimortalidad y los abortos. A comienzos de la década de los '60, la tasa de natalidad superaba los 36,3 por mil habitantes y la mortalidad infantil llegaba a los 120 por mil nacidos vivos. La cobertura hospitalaria del parto era baja y prácticamente 28 madres morían por cada diez mil niños que nacían vivos. Más de un tercio de esas muertes eran consecuencia de abortos clandestinos, teniendo en cuenta que un tercio de los embarazos culminaba en aborto y, del total de éstos, entre un $75 \%$ y un $90 \%$ eran provocados. El grupo más vulnerable lo constituían las mujeres con hasta tres hijos vivos y pertenecientes a los grupos socioeconómicos más bajos.

Ante esta dramática situación, en 1967 el gobierno de Eduardo Frei Montalva formuló la Política de Población y Salud Pública (anteriormente, en 1965, el Servicio Nacional de Salud impulsó la Política Nacional de Regulación de la Fertilidad), con el fin de "garantizar el respeto a la conciencia de las personas y a su dignidad”. Así, se fortalecieron los programas maternoinfantiles y el uso de anticonceptivos orales y del DIU, entre otras medidas.

A lo largo del tiempo, esta política logró importantes resultados. En 1987, el número de abortos hospitalizados había bajado de 56.130, con 306 muertes, que se registraban a mediados de los '60, a 31.986, con 42 fallecimientos. En 1999, la mortalidad materna era de 2,2 por cada 10 mil nacidos vivos, es decir, menos de la décima parte de lo que se observaba en 1965; en tanto, la mortalidad infantil llegó a 10,1 por mil nacidos vivos al finalizar la década de los '90. La disminución del número de hijos por mujer, entre ellos los no deseados, influyó fuertemente en el mejoramiento de estos indicadores.

El decreto que en enero de 2007 estableció las Normas Nacionales sobre Regulación de la Fertilidad da cuenta de estos avances históricos. Asimismo, los fundamentos de las Normas apuntan hacia dos conceptos clave: la paternidad y maternidad responsables -que hombres y mujeres compartan el control y ejercicio de la salud sexual y reproductiva, decidiendo como pareja cuántos hijos desean tener y en qué momento- y el respeto al derecho de los ciudadanos a elegir, en plena conciencia, la opción que más concuerde con sus valores y convicciones.

Las Normas son plenamente coherentes con los Objetivos Sanitarios para la Década 20002010, establecidos por el Ministerio de Salud. Es en ese contexto que el Estado, a través de la red pública de salud y en el marco de la legalidad vigente, tiene el deber de poner a disposición de las personas todas las alternativas disponibles para el control de la natalidad y para que, además, la sexualidad pueda ser ejercida sin riesgos para la salud.

En cuanto a la población adolescente, el Estado tiene la obligación ética y sanitaria de prevenir los embarazos precoces, que constituyen un problema de salud pública de importancia. Sin restar valor al rol orientador de la familia frente a la sexualidad de los adolescentes, corresponde a las autoridades poner al alcance de éstos los métodos de anticoncepción existentes. Así, se enfrenta -a la vez- la dolorosa brecha de inequidad que Chile aún tiene en materia de salud reproductiva, y que puede graficarse con algunas cifras: de los menores de 15 años que ya iniciaron su vida 
sexual, el 18\% pertenece al nivel socioeconómico bajo, mientras que sólo un 5\% corresponde al estrato alto; el $74 \%$ de las madres adolescentes se encuentra en los dos quintiles de menores ingresos; del total de nacidos vivos, los de madres adolescentes representan el 21,6\% en la comuna más pobre de Santiago y el 1,2\% en la más rica. Además, es sabido que el hijo de una madre sin instrucción tiene seis veces más riesgo de morir durante el primer año de vida que uno cuya madre ha llegado a la educación superior.

A fines del año pasado, ante el requerimiento de inconstitucionalidad de las citadas Normas que incluía la eliminación del uso de anticonceptivos orales, del DIU y desde luego del Levonorgestrel en caso de emergencia- presentado por 36 diputados de la Alianza por Chile, el Tribunal Constitucional solicitó la opinión experta de la Facultad de Medicina de la Universidad de Chile.

Un grupo de académicos -pertenecientes al Centro de Medicina Reproductiva y Salud Integral del Adolescente (Cemera), al Departamento de Psiquiatría y Salud Mental y a la Escuela de Salud Pública- expuso los argumentos científicos que demuestran que este método anticonceptivo no es abortivo, ya que no actúa sobre el huevo fecundado, sino antes de que ocurra la fecundación. Pese a ello, el Tribunal Constitucional decidió, por cinco votos contra cuatro, suspender la distribución de los métodos de anticoncepción de emergencia en el sistema público de salud a las mujeres menores de 18 años.

Las consecuencias de esta decisión son graves en varios aspectos. Se vulnera la igualdad de derechos, pues se privilegia al grupo que se opone al uso de la píldora, desconociendo así los derechos de quienes concuerdan con las políticas de control de la fertilidad vigentes. Se está violando el principio básico de la equidad, al declarar ilícita la distribución del medicamento en el sistema público, pues los más afectados serán los grupos de menores ingresos -que son precisamente los usuarios de dicho sistema-, ya que no tendrán acceso a los mismos servicios que el resto de la población.

Resulta curioso constatar que, sin embargo, el fallo no restringe el uso del Dispositivo Intrauterino y de otras hormonas anticonceptivas, en circunstancias que su acción es similar al Levonorgestrel, compuesto que está presente en el 100\% de los anticonceptivos hormonales orales que entrega el Ministerio de Salud y en el $40 \%$ de las píldoras que se compran en las farmacias. Es decir, estamos frente a una incoherencia en la interpretación de la evidencia científica disponible.

En suma, el fallo del Tribunal Constitucional nos pone frente a varias interrogantes, cuyas respuestas, si es que fuera fácil encontrarlas, apuntan más allá de la disponibilidad de un fármaco o de la polémica que siempre es posible esperar ante una nueva normativa. Siendo Chile un país que en muchos ámbitos quiere alcanzar el nivel de los países del mundo desarrollado ¿Estamos avanzando o retrocediendo en materia de salud reproductiva y planificación familiar? ¿Tendremos que enfrentar factores de riesgo maternoinfantiles ya superados? ¿Estamos abordando de manera efectiva la reducción de las brechas de inequidad que todavía hieren el alma de los chilenos? ¿De qué sirven los argumentos y evidencias científicas expuestas por expertos, si finalmente las decisiones son influidas por otro tipo de consideraciones? ¿Podría esta situación repetirse el día de mañana en otros temas que afecten seriamente la salud y la calidad de vida de nuestra población?

Ciertamente, estamos frente a un tema no resuelto.

\author{
Giorgio Solimano \\ Director
}

